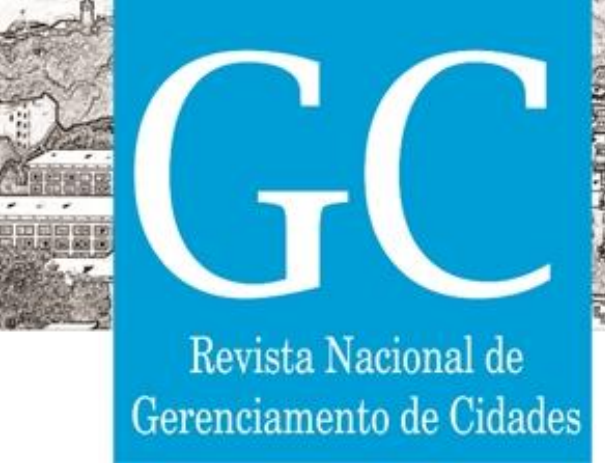

\title{
A cidade e o patrimônio como mercadorias: interferências da indústria cultural na produção do espaço e em práticas de conservação urbana
}

The city and the cultural heritage as commodities: interferences of the cultural industry in spatial production and practices of urban conservation

La ciudad y el patrimonio como mercaderías: interferencias de la industria cultural en la producción del espacio y en prácticas de conservación urbana

Isabela Cristina de Assis Berg

Mestre e Doutoranda em Arquitetura e Urbanismo, UFMG, Brasil isabela.berg@gmail.com 


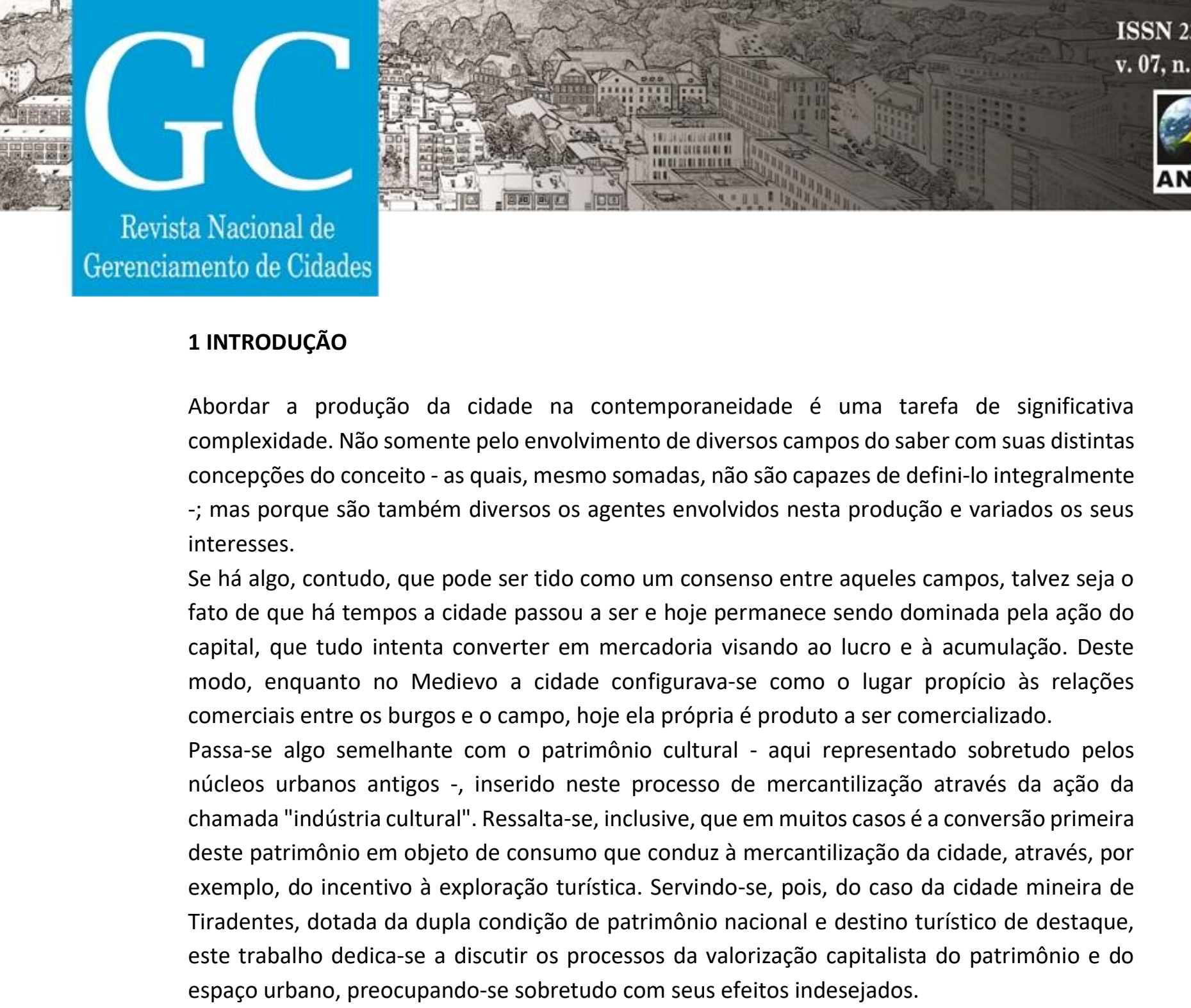

\section{Revista Nacional de}

Gerenciamento de Cidades

\section{INTRODUÇÃo}

Abordar a produção da cidade na contemporaneidade é uma tarefa de significativa complexidade. Não somente pelo envolvimento de diversos campos do saber com suas distintas concepções do conceito - as quais, mesmo somadas, não são capazes de defini-lo integralmente -; mas porque são também diversos os agentes envolvidos nesta produção e variados os seus interesses. fato de que há tempos a cidade passou a ser e hoje permanece sendo dominada pela ação do às relações comerciais entre os burgos e o campo, hoje ela própria é produto a ser comercializado.

Passa-se algo semelhante com o patrimônio cultural - aqui representado sobretudo pelos inserido neste processo de mercantilização através da ação da chamada "indústria cultural". Ressalta-se, inclusive, que em muitos casos é a conversão primeira extrimônio em objeto de consumo que conduz à mercantilização da cidade, através, por 2 RELAÇÕES ENTRE INDÚSTRIA CULTURAL, PATRIMÔNIO E PRODUÇÃO DO ESPAÇO

\subsection{A apropriação capitalista da arte e da cultura: o surgimento da indústria cultural}

O termo "indústria cultural" foi cunhado em meados do século XX por Theodor Adorno e Max Horkheimer para abordar a apropriação das artes erudita e popular pelo modo de produção capitalista e sua consequente conversão em mercadoria. Àquela época a arte começava a ser produzida segundo critérios definidos pela industrialização, como a padronização e a massificação através da difusão de reproduções.

Para os dois filósofos, a criação de um padrão estava relacionada, neste caso, à definição de uma estética ou modo de percepção que facilitasse a assimilação por parte dos indivíduos daquilo em que consistia a arte ou o gosto pela arte, induzindo-os por conseguinte ao consumo de determinados "produtos culturais". Filmes baseados em roteiros com tramas aclamadas pelo público e canções elaboradas a partir do que se difundia como o estilo "da moda" são exemplos comuns. Uma vez inseridos no gosto das massas, ajudavam então a constituir um tipo de ciclo vicioso: passavam a ser ostensivamente reproduzidos e vendidos pelo mercado, reforçando assim a apreciação popular que, por seu turno, ratificava e fortalecia as estratégias adotadas por esse mesmo mercado. 

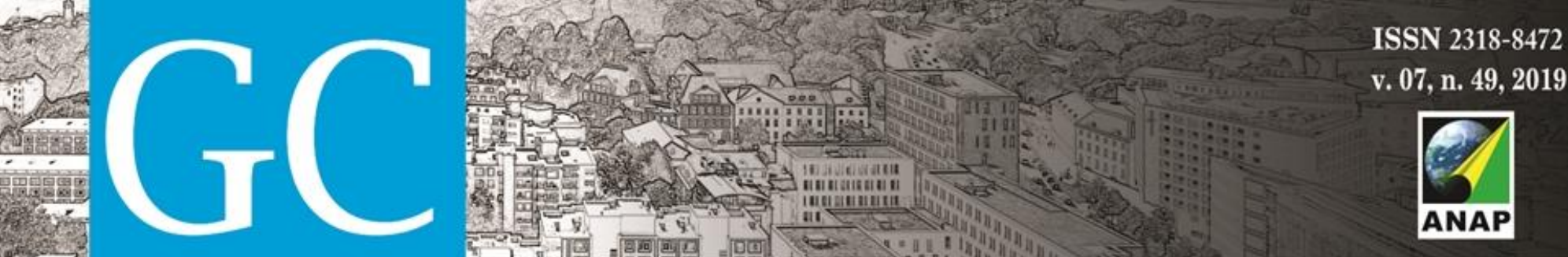

Revista Nacional de

Gerenciamento de Cidades

não no sentido do desejável enaltecimento de seus valores históricos e artísticos, mas sim naquele relativo à atribuição de um valor financeiro. A indústria cultural seria a grande responsável pela exploração deste tipo de valorização e criaria, para tanto, uma verdadeira "engenharia cultural" dotada de estratégias próprias.

No rol dessas estratégias são de certo modo mais comuns e conhecidas as mise-en-scène, com seus espetáculos de luz e som, e as animações culturais, como é o caso de visitas guiadas em museus e o emprego de tecnologias que intermedeiam a relação do indivíduo com as obras. Incluem-se igualmente, com graus de interferência relativamente maiores, as intervenções de modernização, representadas pela inserção de acréscimos contemporâneos destinados a gerar maior atratividade para o bem patrimonial - podendo, por outro lado, gerar o efeito adverso da colocação deste em posição secundária - e a facilitação do acesso - que, não sendo exatamente promoção de acessibilidade, traduz-se em muitos casos na construção de equipamentos urbanos como estacionamentos e outros tipos de complementos que eventualmente desfiguram o entorno dos bens. Nesse sentido, devem ser lembradas sobretudo aquelas ações que consistem em verdadeiros "desvirtuamentos" das boas práticas de restauração e conservação, pois, colocando-se à parte das preocupações com as recomendações do corpus teórico patrimonial reconhecido e vinculadas a outros tipos de interesses, conduzem ora a reconstruções fantasiosas, ora a demolições arbitrárias; tudo sob o pretexto de configurar obras e cenários urbanos mais favoráveis à assimilação do gosto do público e, logo, ao consumo das massas. (CHOAY, 2001, p. 212-218).

A conversão em dinheiro, por fim, como o próprio nome indica é a face mais evidente da valorização patrimonial no sentido financeiro e desdobra-se, por exemplo, desde a locação dos monumentos para a realização de eventos diversos "à sua utilização como suporte publicitário, associando-os à venda de produtos de consumo em geral." (CHOAY, 2001, p. 218). Falamos aqui, pois, de uma gama realmente diversa de produtos: sejam bebidas, itens de vestuário, pacotes de viagem, lugares para se viver.

\subsection{O turismo e o city marketing como agentes da indústria cultural}

O turismo é, certamente, um dos grandes fomentadores da valorização patrimonial. É um nicho de mercado bastante explorado pela indústria cultural e, neste sentido, demanda desta a realização de contínuos investimentos nos locais onde se desenvolve a fim de que sejam cada vez mais atrativos perante seus visitantes. É precipitado, porém, rotulá-lo a priori como prejudicial à preservação, devendo-se reconhecer que

O papel da preservação do patrimônio cultural nacional extrapola, hoje, os limites da história e da memória, uma vez que começa a cumprir um papel econômico e social. Assim, pesquisar sobre a preservação cultural e compreendê-la implica em (sic) desvendar não somente as características culturais, mas, sobretudo, em avaliar possibilidades de ampliar o leque de atividades econômicas dos núcleos urbanos possuidores de acervo cultural. (SIMÃO, 2006, p. 17). 

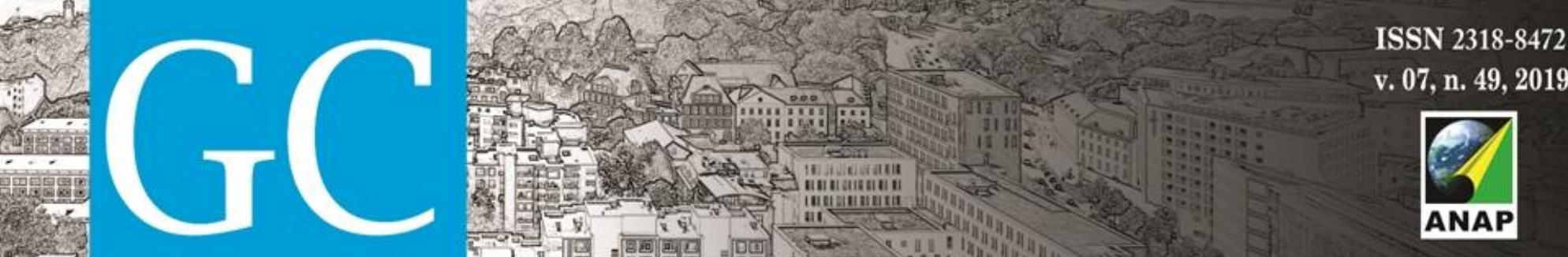

Revista Nacional de

Gerenciamento de Cidades

Entre essas últimas está, pois, a atividade turística, que, como ponderam alguns autores, "pode funcionar como motivadora da manutenção da identidade local" colocando-se "como uma das grandes alternativas econômicas atuais para os núcleos urbanos preservados." (SIMÃO, 2006, p. 18). É necessário, para tanto, que a exploração da atividade turística atenda a três requisitos básicos do ramo, a saber: "a satisfação das necessidades do turista, os benefícios que traz à população residente e a preservação do patrimônio cultural e ambiental." (RODRIGUES, 1996 apud SIMÃO, 2006, p. 19). Ocorre, porém, que em muitos casos essa exploração é feita sem o planejamento adequado, desconsiderando questões como capacidade de carga e gestão dos sítios, fornecimento de infraestrutura e a inclusão de todos os atores sociais no processo, comprometendo assim seus potenciais benefícios.

Vinculado atualmente ao incremento da atividade turística em cidades "históricas" pode-se encontrar o chamado city marketing ou marketing urbano, tipo de planejamento estratégico surgido aproximadamente na década de 1980 com foco na atração de capital para a promoção de desenvolvimento local por intermédio do turismo ou da industrialização. Não raro, entretanto, nota-se que favorece processos ligados à especulação imobiliária e, uma vez associado à indústria cultural, contribui com a conversão do patrimônio em um tipo de mercadoria propícia a estimular, por sua vez, o consumo de determinado lugar. Representa, assim, uma nova estratégia do capital que visa continuamente ampliar seus meios de reprodução e acumulação.

As mercadorias e os objetos mudaram de sentido, posto que, em vez de designar uma coisa simples, articulada com o universo da necessidade imediata, criam-se cada vez mais mercadorias que são estratégias e políticas, como no caso específico do espaço. (CARLOS, 2005 apud JÚNIOR, 2010, p. 90).

A partir daí, ao patrimônio inserido ou coincidente com este espaço são, então, impostas novas configurações.

\subsection{Os dramas da valorização patrimonial: o caso de Tiradentes, em Minas Gerais}

Começa-se a verificar o surgimento dos efeitos negativos da atuação da indústria cultural sobre os núcleos antigos à medida que seu território, posto sob valorização, passa a reservar-se a usos afins ao interesse de determinados grupos e, com isso, a representar espacialmente, nos termos do sociólogo Pierre Bourdieu, "campos" específicos pertencentes a indivíduos com "habitus" específicos. A definição dos campos compreende "um segmento do social, cujos agentes, indivíduos e grupos têm disposições específicas, a que ele denomina habitus" (THIRYCHERQUES, 2006, p. 31); enquanto este último consiste no modo dos indivíduos perceberem, interpretarem e lidarem com a realidade à sua volta. Para Bourdieu, "todo campo se caracteriza por agentes dotados de um mesmo habitus. O campo estrutura o habitus e o habitus constitui 

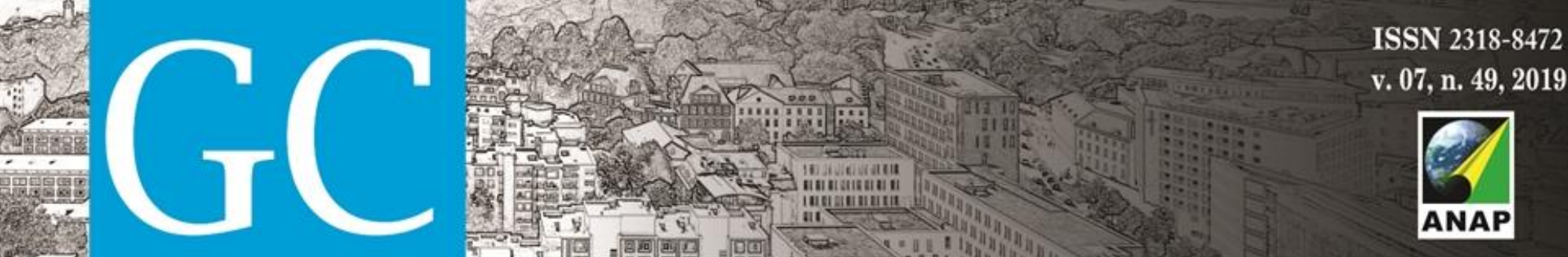

Revista Nacional de

Gerenciamento de Cidades

A divulgação midiática das características pitorescas do município e da oferta de estabelecimentos criados para o atendimento do turista em busca de lazer e cultura foi a responsável pelo seu boom e, consequentemente, por transformações em vários aspectos da dinâmica local. Citando um exemplo, em relatório da Fundação João Pinheiro (FJP) divulgado em 1977, o artesanato em prata figurava como atividade principal (p. 89), enquanto hoje esta corresponde exatamente ao turismo (BOLSON, FERREIRA e VIEIRA FILHO, 2006, p. 35), estimulado não somente pelo seu patrimônio edificado e natural, mas também pela criação de eventos de grande projeção como a Mostra de Cinema e o Festival de Gastronomia. A própria FJP, que àquela época também havia se dedicado à elaboração de um plano para o desenvolvimento tiradentino, admitia a "necessidade de se apoiar a função turismo desempenhada pela cidade, função esta decorrente de sua representatividade histórica e valor artístico, traduzida espacialmente pela estrutura urbana e a paisagem/cenário envolvente." (FJP, 1980, p. 1).

O trabalho da instituição, estendido a outros municípios vizinhos como São João del-Rei, demonstrava assim o reconhecimento do turismo como um potencial promotor de desenvolvimento local e regional, mas também a percepção de que, para que isto ocorresse, seria necessário dispor do planejamento adequado - o que a nível municipal àquele tempo não houve e atualmente permanece inexistente:

Foi perguntado aos entrevistados se existe o hábito de se planejar o município de Tiradentes, e a resposta negativa foi unânime: "Não, não há secretaria de planejamento aqui". "Não, não há plano estratégico nem plano diretor. É difícil se planejar pois não temos técnicos qualificados." "Não há plano municipal de turismo. Falta visão." (BOLSON, FERREIRA e VIEIRA FILHO, 2006, p. 37).

Mas, deve-se reconhecer que o city marketing aplicado à cidade somente foi possibilitado pela associação entre o setor privado e o poder público num arranjo de forças para "vender a cidade", configurando um processo segundo o qual

Os comércios se densificam no centro, que atrai os comércios raros, os produtos e
gêneros de luxo. Esta centralidade se instala com predileção nos antigos núcleos, nos
espaços apropriados no decorrer da história anterior. [...] Nesses lugares privilegiados,
o consumidor também vem consumir o espaço; o aglomerado de objetos nas lojas,
vitrinas, mostras, torna-se a razão e pretexto para a reunião das pessoas; elas olham,
vêem (sic), falam, falam-se. E é o lugar de encontro, a partir do aglomerado das coisas.
Aquilo que se diz e se escreve é antes de mais nada o mundo da mercadoria, a
linguagem das mercadorias, a glória e a extensão do valor de troca. (LEFEBVRE, 1996,
apud MADUREIRA, 2011, p. 100).

Nota-se que há, então, uma questão relativa ao atendimento de interesses específicos e a criação desse "lugar-mercadoria", voltado ao consumo de alguns, fez com que Tiradentes, que 

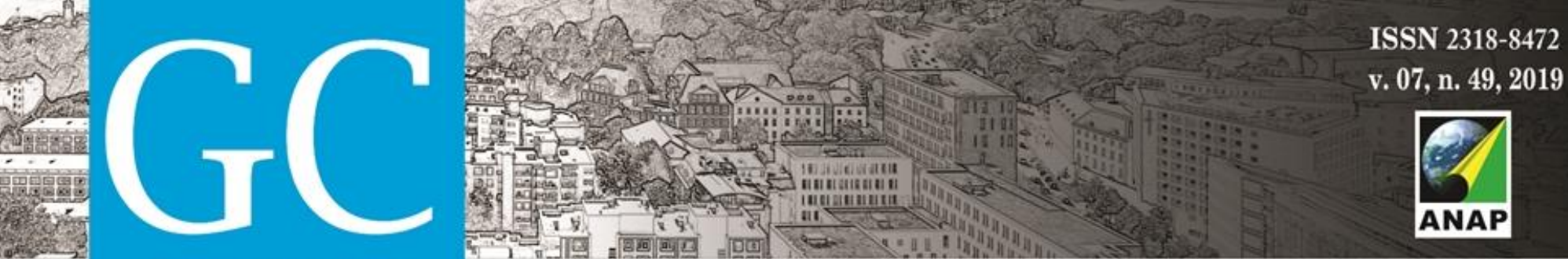

Revista Nacional de Gerenciamento de Cidades

mais profundo, pertencente aos domínios da própria ética. Há, portanto, ainda muito trabalho a realizar, ainda um longo caminho a percorrer.

\section{REFERÊNCIAS BIBLIOGRÁFICAS}

BENJAMIN, Walter. A obra de arte na era de sua reprodutibilidade técnica. 1955. Disponível em: < https://philarchive.org/archive/DIATAT >. Acesso em: abr. 2019.

BOLSON, J.; FERREIRA, M. A. T.; VIEIRA FILHO, N. A. Q. Os impactos do turismo em Tiradentes: uma análise da percepção do setor público local. Reuna, Belo Horizonte, v. 11, n. 1, p. 29-40, 2006. Disponível em:

<http://www.repositorio.fjp.mg.gov.br/handle/123456789/127>. Acesso em: abr. 2019.

CAMPOS, Helcio Ribeiro. Transformações urbanas recentes em Tiradentes - MG: anos 80 e 90 do século XX. 2006, 183 p. Dissertação (Mestrado) - Faculdade de Filosofia, Letras e Ciências Humanas, Universidade de São Paulo, São Paulo, 2006.

CHOAY, Françoise. A alegoria do patrimônio. Tradução: Luciano Vieira Machado. Ed. Unesp: São Paulo, 2001. FUNDAÇÃO JOÃO PINHEIRO. Micro Região dos Campos das Vertentes: estudo preliminar e diretrizes de desenvolvimento. Belo Horizonte: Fundação João Pinheiro, 1977, v. 1. Disponível em: $<$ http://www.bibliotecadigital.mg.gov.br/consulta/consultaDetalheDocumento.php?iCo dDocumento=49017>. Acesso em: abr. 2019.

FUNDAÇÃO JOÃO PINHEIRO. Circuito do Ouro Campos das Vertentes: plano de organização espacial e preservação do centro histórico de Tiradentes. Belo Horizonte: Fundação João Pinheiro, 1980. 7 v.. Disponível em: <http://www.bibliotecadigital.mg.gov.br/consulta/consultaDetalheDocumento.php?iCodDocumento=48887>. Acesso em: abr. 2019.

HOLLOWAY, J. Fissuras: a antipolítica da dignidade. In: Fissurar o capitalismo. São Paulo: Publisher Brasil, 2013.

INSTITUTO BRASILEIRO DE GEOGRAFIA E ESTATÍSTICA. Tiradentes: panorama. [Censo de] 2010. Disponível em: $<$ https://cidades.ibge.gov.br/brasil/mg/tiradentes/panorama>. Acesso em: abr. 2019.

JÚNIOR, Atilio Marchesini. O modelo estratégico de "city marketing" e suas escalas de atuação. Espaço em Revista, Goiás, vol. 12, no 2, p. 84-101, jul/dez. 2010.

LEFEBVRE, Henri. O direito à cidade. Tradução de Rubens Eduardo Frias. São Paulo: Centauro, 2001.

MADUREIRA, Mariana Alves. A construção do Largo das Forras como patrimônio. 2011, 149 p. Dissertação (Mestrado) - Faculdade de Arquitetura e Urbanismo, Universidade de São Paulo, São Paulo, 2011.

MINISTÉRIO DO TURISMO. Índice de competitividade do turismo nacional: Tiradentes. 2015. Disponível em: <http://www.turismo.gov.br/sites/default/turismo/o ministerio/publicacoes/Indice competitividade/2015/Tiraden tes RA 2015.pdf >. Acesso em: abr. 2019.

QUEIROZ, Francisco; PORTELA, Ana Margarida. Conservação urbana e territorial integrada: reflexões sobre salvaguarda, reabilitação e gestão de centros históricos em Portugal. Lisboa: Livros Horizonte, 2009.

SIMÃO, Maria Cristina Rocha. Preservação do patrimônio cultural em cidades. Editora Autêntica: Belo Horizonte, 2006.

THIRY-CHERQUES, H. R. Pierre Bourdieu: a teoria na prática. RAP, Rio de Janeiro, n.40, v.1, p. 27-55, Jan./Fev. 2006. 